\title{
Photocatalytic selective 1,2-hydroxyacylmethylation of 1,3-dienes with sulfur ylides as source of alkyl radicals
}

\author{
Shuang-Hua Xu, ${ }^{a}$ Dong-Mei Yan, ${ }^{a}$ Li Rao, ${ }^{a}$ Min Jiang, ${ }^{b}$ Ya-Li Wu, ${ }^{a}$ Wen-Jing Xiao, ${ }^{a}$ and Jia-Rong \\ Chen $^{\mathrm{a}, \mathrm{c}^{*}}$
}

\begin{abstract}
Exploration of the zwitterionic property of sulfur ylides has long been known as a flexible strategy in a wide range of chemical transformations for different ring-sized construction. By contrast, their use in radical synthetic chemistry has been significantly limited due to dearth of general activation methods. Herein, a convenient strategy of visible light-driven proton-coupled electron transfer was reported to enable sulfur ylides to decompose into the corresponding $\alpha$-carbonyl carbon radicals. With this method, a highly selective 1,2-hydroxyacylmethylation between 1,3-dienes, sulfur ylides and water under photoredox catalysis is thus achieved (>40 examples). Preliminary mechanistic studies and theoretical calculations shed light on the mechanism and the origin of regioselectivity.
\end{abstract}

Exploration of the zwitterionic property of sulfur ylides has long been known as a versatile strategy in a wide range of chemical transformations for different ring-sized construction. ${ }^{1}$ Some of the these thermal reactions have also become textbook knowledge. In comparision to these ionic chemistry, use of sulfur ylides in radical synthetic chemistry has been significantly limited due to dearth of general activation methods, though direct photolysis of sulfur ylides ${ }^{2}$ and theoretical studies ${ }^{3}$ on sulfur ylide radical cations have been the subject of studies for more than five decades. Some of these early studies also disclosed that the chemical reactivity of sulfur ylide radical cations, generated from sulfur ylides by single electron transfer (SET) oxidation, were highly dependent on their substitution patterns. For instance, a pioneering study of Schuster revealed that stabilized sulfur ylides could undergo visible light-driven SET-oxidation to form sulfur ylide radical cations, when using 9,10-dicyanoanthracene (DCA) as a photocatalyst. ${ }^{4}$ However, mixtures of different products consisting of cyclopropanes and alkenes were observed. Building on this work and by employing the reactivity of sulfur ylide radical cations, we have recently developed a range of photoredox-catalyzed radical coupling reactions of sulfur ylides. ${ }^{5}$ Key to the success of these processes

${ }^{a}$ CCNU-uOttawa Joint Research Centre, Key Laboratory of Pesticide \& Chemica Biology, Ministry of Education; College of Chemistry, Central China Norma University, 152 Luoyu Road, Wuhan, Hubei 430079, China. E-mail: chenjiarong@mail.ccnu.edu.cn

${ }^{b}$ College of Materials, Chemistry and Chemical Engineering, Hangzhou Normal University, 2318 Yuhangtang Road, Hangzhou 310036, China

'School of Chemistry and Chemical Engineering, Henan Normal University, 46 East of Construction Road, Xinxiang 453007, China is the controlled generation of sulfur ylide radical cations through a SET-oxidation event under photocataltyic conditions (Scheme 1a). On the basis of these studies, we attempted to further explore the synthetic potential of sulfur ylides in radical chemistry. Thus, we envisioned development of a distinct catalytic activation platform for decomposion of sulfur ylides into their corresponding neutral alkyl radicals rather than radical cations, given the wide applications of carbon-centred radicals in radical transformations. ${ }^{6}$

With the introduction of visible light photoredox catalytic methods for the generation of various open-shell species under mild conditions, ${ }^{7}$ sulfonium salts have been indentified to be a versatile class of precursors to form the relevant carboncentred radicals upon SET-reduction-triggered $\mathrm{C}-\mathrm{S}$ bond cleavage (Scheme 1a). ${ }^{8,9}$ A series of outstanding works from the groups of Ritter, ${ }^{10}$ Wang, ${ }^{11}$ Procter, ${ }^{12} \mathrm{Shi}^{13}{ }^{13}$ Alcarrazo, ${ }^{14}$ and Yang ${ }^{15}$ established that a range of aryl, alkyl, and $\alpha$-diazo sulfonium salts could serve as competent source of functionalized aryl and alkyl radicals to particiapte in diverse C$\mathrm{C}$ and C-heteroatom bond-forming reations through photoredox cycles. Despite these impressive contributions, to our knowledge, less reactive and stabilized sulfur ylides such as these derived from $\alpha$-bromocarbonyl compounds, have yet to been exploited for the generation of the relevant $\alpha$-carbonyl carbon radicals. As part of our interest in the photoredox catalysis ${ }^{16}$ and sulfur ylide chemistry, ${ }^{5}$ we wondered whether the merger of visible light photoredox catalysis and protoncoupled electron transfer (PCET) ${ }^{17}$ would provide a new approach for conversion of sulfur ylides to the corresponding alkyl radicals in a controlled manner (Scheme 1a). Since the work of Kellogg on the photoinduced SET-reduction-mediated generation of $\alpha$-carbonyl carbon radicals from the $\alpha$ bromocarbonyl compounds, ${ }^{18} \alpha$-carbonyl alkyl bromides have found extensive in numerous photoredox catalyzed radical cross-couplings. ${ }^{19,20}$ However, such compound class, in some instances, have been plagued by their low reactivity and susceptibility to thermal nucleophilic substitution due to the good leaving ability of bromide. The resultant bromide anions are also oxidation labile species. To overcome these potential challenges, MacMillan ${ }^{21 a, b}$ and Zeitler ${ }^{21 c}$ documented that $\alpha$ acetoxy acetophenones provided an elegant alternative class of precursors towards $\alpha$-carbonyl carbon radicals. If successful, thus, our method would complement existing methods for catalytic generation of $\alpha$-carbonyl carbon radicals, while circumventing the possible side reactions and efficiency issues 
encountered in the direct use of sulfonium salts or $\alpha$-bromo carbonyl compounds.

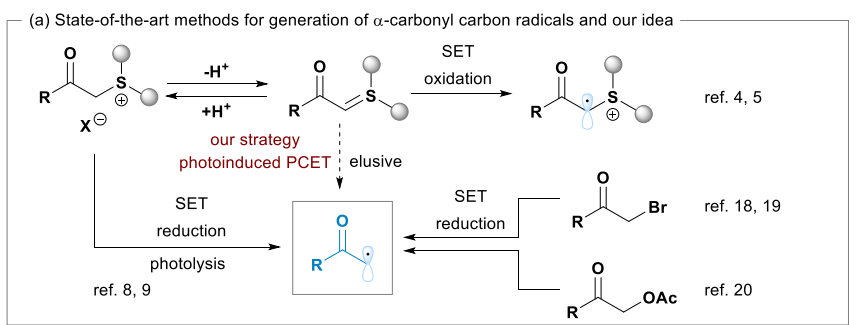

(b) This work: selective 1,2-hydroxyacylmethylation of 1,3-dienes with sulfur ylides as radical source

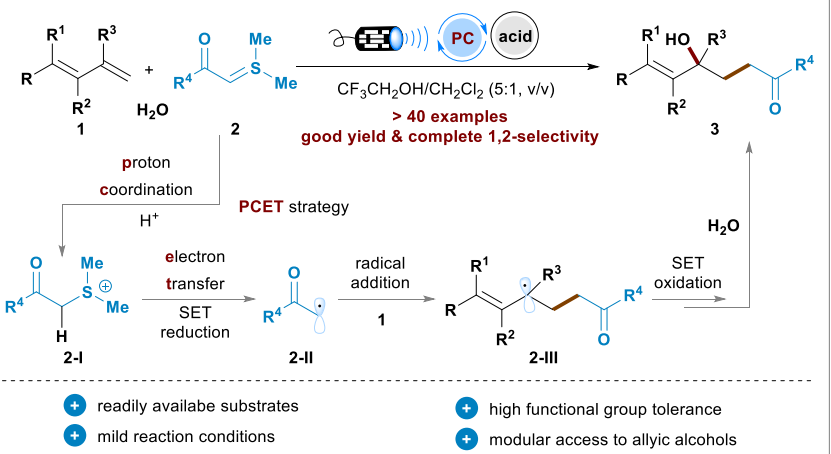

Scheme 1 Background. (a) State-of-the-art light-induced methods for the generation of $\alpha$-carbonyl carbon radicals and our methods. (b) Our reaction design and working hypothesis. $\mathrm{SET}=$ single electron transfer. $\mathrm{PC}=$ photocatalyst.

With the evolvement of photoredox catalysis, ${ }^{7}$ visible lightdriven radical-mediated 1,4- and 1,2-difunctionalization of 1,3dienes and derivatives has emerged as a powerful paradigm for simultaneous installation of carbon-carbon and/or carbonheteroatom bonds. ${ }^{22}$ The resultant allylic compounds are useful synthetic building blocks because of their unique structural characteristics. The majority of these reactions were triggered by addition of photogenerated carbon-centred radicals to the terminal alkene moiety. Notwithstanding the impressive advances, some challenges still remain, such as expansion of the current pool of radical precursors and coupling partners, as well as selectivity caused by the inherent structural property of 1,3dienes. Building our recent achievements on tandem radical addition and $\mathrm{C}-\mathrm{O}$ coupling reactions of 1,3-dienes ${ }^{23}$ and design plan for activation of sulfur ylides (Scheme 1a), we became interested in investigating selective 1,2hydroxyacylmethylation of 1,3-dienes with sulfur ylides as source of alkyl radicals and water as a nucleophile (Scheme 1b). The achievement of this reaction would provide a practical method for preparation of valuable ketone-containing allylic alcohols, complementing the existing radical-involved allylic functionalization. ${ }^{24}$ In addition to activation of sulfur ylides, however, several other challenges might also be considered, such as efficient trap of $\alpha$-carbonyl carbon radical by 1,3 -dienes, control of the regioselectivity during the couping between nucleophile and allylic radical intermediate that was often met in the radical reactions of 1,3-dienes. Herein, we report how this idea was translated into experimental reality, enabling the target selective 1,2-hydroxyacylmethylation reaction of 1,3dienes.

Table 1 Condition optimisation ${ }^{a}$

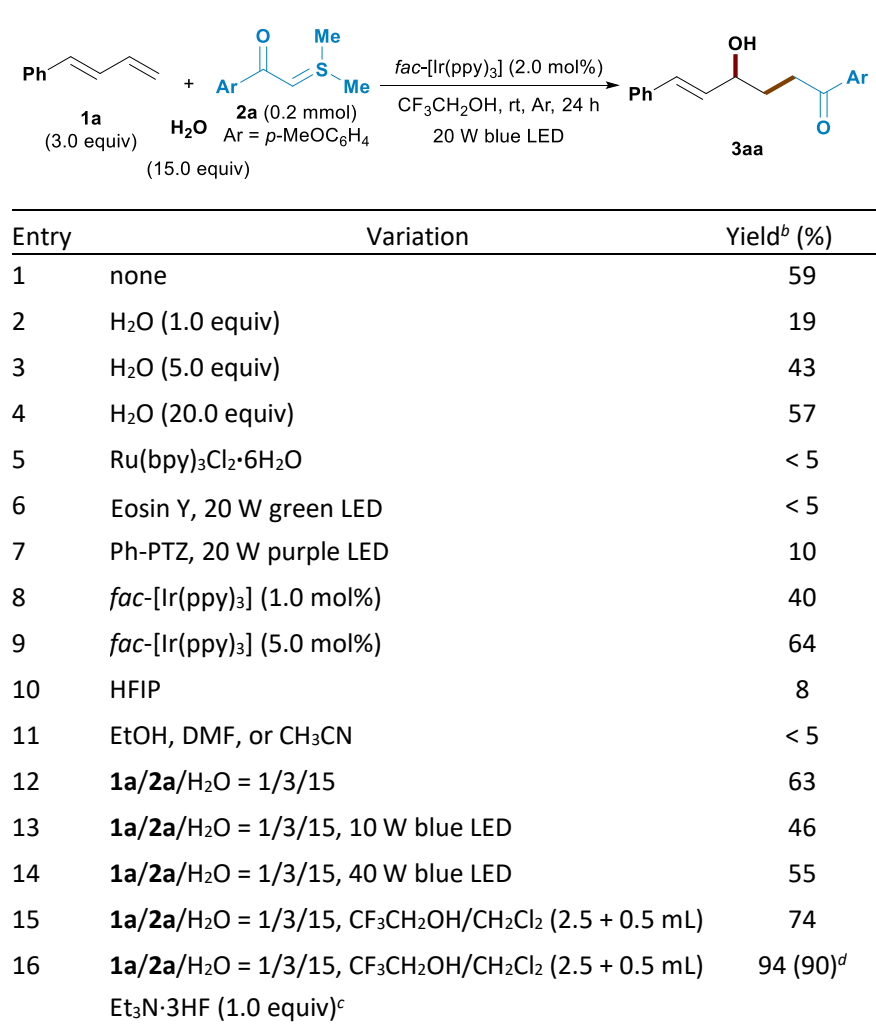

${ }^{a}$ Reaction conditions: 1 a ( $0.60 \mathrm{mmol}, 3.0$ equiv), 2 a $(0.20 \mathrm{mmol}), \mathrm{H}_{2} \mathrm{O}$ (3.0 mmol, 15.0 equiv), and fac-[Ir(ppy) 3 ] $(0.004 \mathrm{mmol}, 2.0 \mathrm{~mol} \%)$, in $\mathrm{CF}_{3} \mathrm{CH}_{2} \mathrm{OH}(2.0 \mathrm{~mL})$ at $\mathrm{rt}$ under argon atmosphere and the irradiation of $20 \mathrm{~W}$ blue LED $(450-460 \mathrm{~nm}$, distance ca. $3 \mathrm{~cm})$ for $24 \mathrm{~h} .{ }^{b}$ Determined by ${ }^{1} \mathrm{H}$ NMR analysis using 1,3,5-trimethoxybenzene as an internal standard. ${ }^{c}$ Reaction time shortened to $7 \mathrm{~h} .{ }^{d}$ Isolated yield. HFIP = 1,1,1,3,3,3-hexafluoro-2-propanol.

Initially, we examined the feasibility of the designed threecomponent 1,2-hydroxyacylmethylation reaction using 1phenylbutadiene $\mathbf{1 a}$, sulfur ylide $\mathbf{2 a}$ and $\mathrm{H}_{2} \mathrm{O}$ as the model substrates with $3 / 1 / 15$ equivalent ratio (Table 1 ). ${ }^{25}$ The representative optimization results are highlighted in Table 1. Pleasingly, the desired reaction could indeed work smoothly to form 1,2-adduct product 3aa exclusively in 59\% NMR yield, when using $\mathrm{fac}_{-}\left[\mathrm{Ir}(\mathrm{ppy})_{3}\right]$ as the photocatalyst in $\mathrm{CF}_{3} \mathrm{CH}_{2} \mathrm{OH}$ as solvent under irradiation of a $20 \mathrm{~W}$ blue LED at room temperature for $24 \mathrm{~h}$ (entry 1 ). During optimization studies, it was found that the reaction was very sensitive to the amounts of $\mathrm{H}_{2} \mathrm{O}$, photocatalysts and reaction media. As shown in entries 2-4, varying stoichiometry of $\mathrm{H}_{2} \mathrm{O}$ has an obvious effect on the reaction effciency, and a fifteenfold amount of $\mathrm{H}_{2} \mathrm{O}$ was the best of choice. Next, we screened several other commonly used Ir(III) and $\mathrm{Ru}(\mathrm{II})$ photocatalysts as well as organic photocatalysts. Among them, only organic photocatalyst 10phenylphenothiazine (Ph-PTZ) gave a 10\% yield of 3aa (entry 7 ), 
while the others resulted in very low conversion or messy mixture. As $1 \mathrm{~mol} \%$ or $5 \mathrm{~mol} \%$ loading of photocatalyt fac$\left[\operatorname{Ir}(\mathrm{ppy})_{3}\right]$ did not lead to significant improvement of the yield (entries 8 and 9), a 2 mol\% loading was used for further optimisation in terms of cost and efficiency. An extensive survey of solvents was also performed and it was found that $\mathrm{CF}_{3} \mathrm{CH}_{2} \mathrm{OH}$ was still optimal. Other solvents such as EtOH, DMF and $\mathrm{CH}_{3} \mathrm{CN}$ completely inhibited the desired reactivity (entry 11), while 1,1,1,3,3,3-hexafluoro-2-propanol (HFIP) resulted in trace amount of 3aa (entry 10 ). These results implied that $\mathrm{CF}_{3} \mathrm{CH}_{2} \mathrm{OH}$ might serve as a proton source to participate in the activation of sulfur ylide $\mathbf{2 a}$.

Upon further screening of various equivalent ratios of $\mathbf{1 a}, \mathbf{2 a}$ and $\mathrm{H}_{2} \mathrm{O}$, it was established that the yield was increased to $63 \%$, when using 1-phenylbutadiene 1a as limiting reagent with threefold and fifteenfold excess of $2 \mathrm{a}$ and $\mathrm{H}_{2} \mathrm{O}$, respectively (entry 12). Using such a ratio of three reaction components, we proceeded to screen other parameters regarding light intensity, concentration and additives. Though the decrease and increase of light intensity both resulted in an decrease of yield (entries 13 and 14), a mixture solvent system of $\mathrm{CF}_{3} \mathrm{CH}_{2} \mathrm{OH} / \mathrm{CH}_{2} \mathrm{Cl}_{2}(5 / 1$, $\mathrm{v} / \mathrm{v}$ ) and a concentration of $0.067 \mathrm{M}$ increased the yield to $74 \%$ (entry 15). Interestingly, we found that the reaction outcome was also greatly influenced by the acidity/basicity of the reaction mixture. An extensive screen of additives identified $\mathrm{Et}_{3} \mathrm{~N} \cdot 3 \mathrm{HF}$ (1.0 equiv) to be optimal, with 3aa being isolated in $90 \%$ yield (entry 16). Finally, a series of control experiments confirmed that photocatalyst and visible light irradiation are both critical to the reaction. ${ }^{25}$

Having established effective conditions for selective 1,2hydroxyacylmethylation of 1-phenylbutadiene 1a, we first investigated the scope of 1,3-dienes. The results are highlighted in Table 2. As for 1-aryl-1,3-butadienes, there is no obvious requirement for electronic properties or specific substitution patterns in this system. For instance, in addition to $\mathbf{1 a}$, a range of 1-aryl-1,3-butadiene derivatives $\mathbf{1} \mathbf{b}$-p bearing an electrondonating (e.g., $\mathrm{Me}, \mathrm{OMe}, t$-Bu) or electron-withdrawing (e.g., $\mathrm{F}$, $\mathrm{Cl}, \mathrm{Br}, \mathrm{CF}_{3}$ and $\mathrm{OCF}_{3}$ ) substituent at para-, ortho- or metaposition of the aromatic ring all react smoothly to give $\mathbf{3 b a}$-pa with generally good efficiency (51-96\% yield). Moreover, 1,3dienes 1q having 3-thiophenyl and 1r with 2-naphthyl group also prove to be compatible with the reaction, affording the expected products $3 q a$ and 3 ra in $74 \%$ and $65 \%$ yields, respectively. Notably, as shown in the case of substrates $1 \mathrm{~s}$ and 1t with disubstituted phenyl ring, the increased steric hindrance of phenyl ring has no deleterious effect on the reaction, with the corresponding product 3sa and 3ta being obtained with good yields. Note that these products (e.g., 3ea-ga, 3ia-ja and 3oa-pa) bearing halogen functionalities such as $\mathrm{F}, \mathrm{Br}$, and $\mathrm{Cl}$, offer excellent handles for further synthetic elaborations. Encouraged by these results, we extended the protocol to some disubstituted 1,3-dienes to construct structurally more complex allylic alcohols. Under the standard conditions, 1,1-diphenyl substituted $\mathbf{1 u}$, and $\mathbf{1} \mathbf{v}$ and $\mathbf{1} \mathbf{w}$ having a methyl group at the C2 and C3 position are all well tolerated, furnishing the expected products 3ua-wa in satisfactory yields (54-91\% yields). Remarkably, the current catalytic system also proved to be suitable for challenging alkyl-substituted 1,3-diene 1x, allowing exclusive formation of the desired 1,2-hydroxyacylmethylated product 3xa in $63 \%$ yield. Such type of 1,3-dienes typically resulted in formation of mixtures of 1,2-and 1,4-adducts in our previously reported photo-induced copper-catalyzed C-O crosscoupling reactions. ${ }^{23}$

Table 2 Scope of 1,3-dienes ${ }^{a, b}$

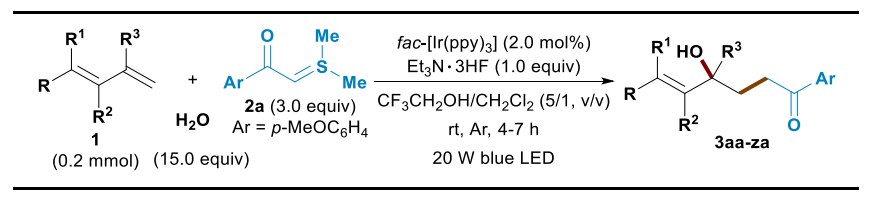

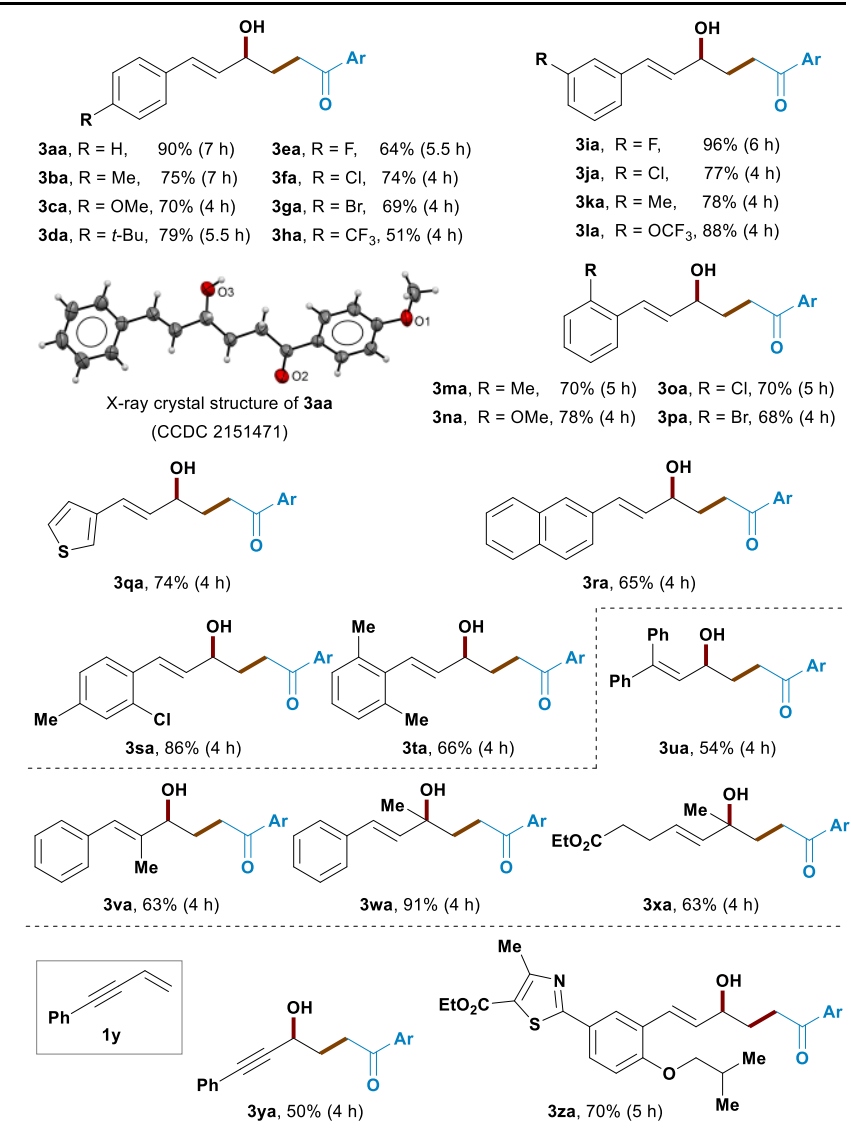

a Reaction conditions: 1 ( $0.20 \mathrm{mmol}), 2 \mathrm{2a}(0.60 \mathrm{mmol}, 3.0$ equiv), $\mathrm{H}_{2} \mathrm{O}$ ( $3.0 \mathrm{mmol}, 15.0$ equiv), $\mathrm{Et}{ }_{3} \mathrm{~N} \cdot 3 \mathrm{HF}$ ( $0.2 \mathrm{mmol}, 1.0$ equiv), and fac-[Ir(ppy) $\left.)_{3}\right](0.004 \mathrm{mmol}, 2.0 \mathrm{~mol} \%)$, in a mixture of $\mathrm{CF}_{3} \mathrm{CH}_{2} \mathrm{OH}$ $(2.5 \mathrm{~mL})$ and $\mathrm{CH}_{2} \mathrm{Cl}_{2}(0.5 \mathrm{~mL})$ at $\mathrm{rt}$ under argon atmosphere and the irradiation of $20 \mathrm{~W}$ blue LED $(450-460 \mathrm{~nm}$, distance ca. $3 \mathrm{~cm})$ for 4-7 h. ${ }^{b}$ Isolated yield.

Notably, as for the radical acceptors, the current protocol is not limited to 1,3-dienes. Under the optimal reaction conditions, 1-phenyl-1,3-enylene 1y also works well to give propargylic alcohol 3ya in $50 \%$ yield. A pharmaceutical febuxostat-derived 1,3-diene $\mathbf{1 z}$ also proves to be compatible with the reaction system, producing $3 z a$ in $70 \%$ yield.

Then, we turned our attention to explore the generality of the protocol by reacting a representative set of stabilized sulfur ylides 2 with $1 \mathrm{a}$ and $\mathrm{H}_{2} \mathrm{O}$ under the standard conditions (Table 3). Again, it was found that the electronic characteristics and the substitution patterns of the aromatic ring of sulfur ylides do not have any obvious effect on the three-component reaction. For 
instance, aside from model substrate $\mathbf{2 a}$, an array of $\alpha$ bromocarbonyl compound-derived sulfur ylides $\mathbf{2} \mathbf{b}-\mathbf{k}$ bearing neutral (2b), electron-donating (e.g., Me, OMe) and electronwithdrawing (e.g., $\mathrm{F}, \mathrm{Cl}, \mathrm{Br}$ ) at the para-, meta- or ortho-position of the phenyl ring are all well accommodated. Products 3ab-ak are thus achieved in yields ranging from $50-92 \%$. As shown in the synthesis of 3al, sterically demanding multiply substituted sulfur ylide $\mathbf{2 l}$ also reacts to give a $79 \%$ yield. Markedly, both 2thiophene- and 2-natphthyl-substituted sulfur ylides $\mathbf{2 m}$ and $\mathbf{2 n}$ are also competent radical precursors, giving rise to the corresponding products 3am and 3an in $81 \%$ and $86 \%$ yields, respectively. As a limitation of the current reaction system, alkyl-substituted sulfur ylides do not react under the standard conditions, which might await further condition optimisation.

Table 3 Scope of sulfur ylides ${ }^{a, b}$

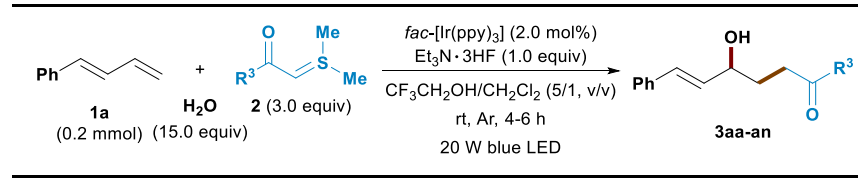

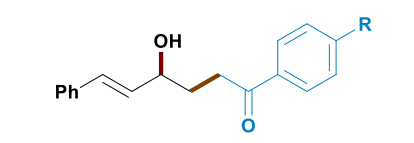

3aa, $R=O M e, 90 \%(4 \mathrm{~h}) \quad$ 3ad, $R=F, \quad 92 \%(5.5 \mathrm{~h})$ 3ab, $\mathrm{R}=\mathrm{H}, \quad 68 \%(4 \mathrm{~h}) \quad$ 3ae, $\mathrm{R}=\mathrm{Cl}, 75 \%(6 \mathrm{~h})$ 3ac, $R=M e, \quad 83 \%(4 h) \quad 3 a f, R=B r, 64 \%(4 h)$ 3aj, $\mathrm{R}=\mathrm{OMe}, 73 \%(5 \mathrm{~h})$

3ak, $R=F, \quad 83 \%(4 \mathrm{~h})$

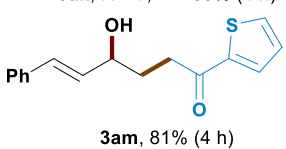

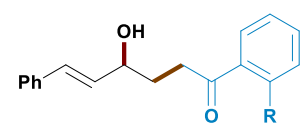

3am, $81 \%(4 \mathrm{~h})$

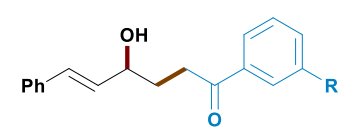

3ag, $R=O M e, 78 \%(4 \mathrm{~h})$

3ah, $R=F, \quad 85 \%(4 \mathrm{~h})$

3ai, $\mathrm{R}=\mathrm{Br}, \quad 50 \%(4 \mathrm{~h})$

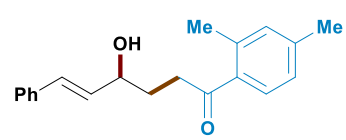

3al, $79 \%(4 h)$

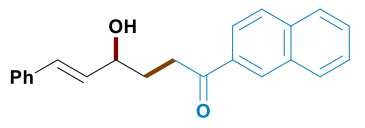

3an, $86 \%$ (4 h)
${ }^{a}$ Reaction conditions: $1 \mathrm{a}(0.20 \mathrm{mmol}), \mathbf{2}(0.60 \mathrm{mmol}, 3.0$ equiv), $\mathrm{H}_{2} \mathrm{O}$ ( $3.0 \mathrm{mmol}, 15.0$ equiv), $\mathrm{Et}_{3} \mathrm{~N} \cdot 3 \mathrm{HF}$ ( $0.2 \mathrm{mmol}, 1.0$ equiv), and fac-[Ir(ppy) $)_{3}$ (0.004 mmol, $\left.2.0 \mathrm{~mol} \%\right)$, in a mixture of $\mathrm{CF}_{3} \mathrm{CH}_{2} \mathrm{OH}$ $(2.5 \mathrm{~mL})$ and $\mathrm{CH}_{2} \mathrm{Cl}_{2}(0.5 \mathrm{~mL})$ at $\mathrm{rt}$ under argon atmosphere and the irradiation of $20 \mathrm{~W}$ blue LED $(450-460 \mathrm{~nm}$, distance ca. $3 \mathrm{~cm})$ for 4-6 h. ${ }^{b}$ Isolated yield.

To demonstrate the synthetic potential of this protocol, we also performed the three-component reaction of $\mathbf{1 a}, \mathbf{2 a}$ and $\mathrm{H}_{2} \mathrm{O}$ on a $5.0 \mathrm{mmol}$ scale, and comparable results can still be achieved (3aa, $1.38 \mathrm{~g}, 88 \%$ yield) (Scheme 2a). As the allylic alcohol and ketone are versatile handles for synthetic transformations, several derivatizations product 3aa were carried out (Scheme $2 b$ ). For example, upon routine oxidation of the free alcohol moiety with DMP, the corresponding valuable building block 1,4-dione 4 can be isolated in $80 \%$ yield. Surprisingly, under Appel reaction conditions, ${ }^{26 a}$ dehydration product, 1,3-diene 5, is obtained in $72 \%$ yield after $24 \mathrm{~h}$ rather than the proposed allylic halide. Moreover, further treatment of 3aa with $\mathrm{CF}_{3} \mathrm{CH}_{2} \mathrm{OH}$ as both a nucleophile and solvent in the presence of $\mathrm{Et}_{3} \mathrm{~N} \cdot 3 \mathrm{HF}$ gives the trifluoroethoxylation product 6 in $90 \%$ yield. ${ }^{26 b}$ With Fernandes' Pd-catalyzed intramolecular $O$ allylation methodology, ${ }^{26 c}$ the $\gamma$-acetoxy- $\delta, \varepsilon$-unsaturated ketoxime 7 easily derived from 3aa can undergo intramolecular 6-exo $O$-allylation efficiently to provide biologically relevant oxazine 8 in $68 \%$ yield.

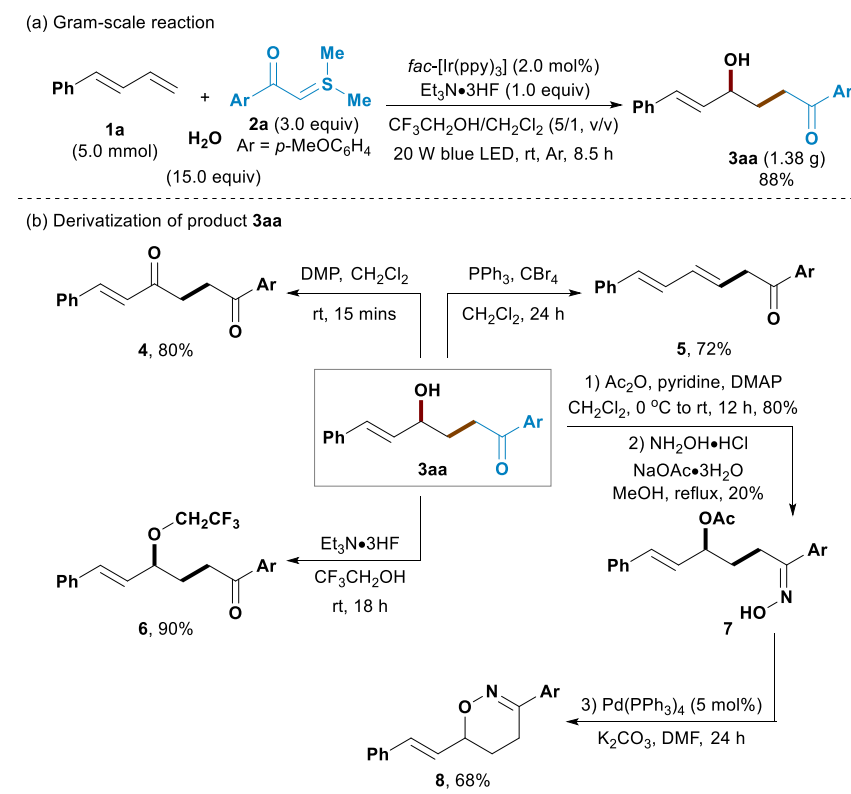

Scheme 2 Synthetic utility. DMP = 1,1,1-Triacetoxy-1,1-dihydro1,2-benziodoxol-3(1H)-one. (Dimethylamino)pyridine. Derivatization of product.

(a) Gram-scale reaction.

In order to gain some insight into the reaction mechanism, we carried out a range of mechanistic studies. First, when stoichiometric radical scavengers 2,2,6,6-tetramethyl-1piperidinyloxy (TEMPO) (3.0 equiv) or PhSeSePh (3.0 equiv) were added to the model reaction, the formation of desired product 3aa was completely inhibited; instead, radical trapping TEMPO-adduct 9 and PhSe-adduct $\mathbf{1 0}$ could be isolated with $10 \%$ and $57 \%$ yield, respectively (Scheme $3 a$ ). These results suggest that the $\alpha$-carbonyl carbon radical $\mathbf{2 a - I I}$ and a radical process might be involved in our reaction. Moreover, when replacing $\mathrm{H}_{2}{ }^{16} \mathrm{O}$ with $\mathrm{H}_{2}{ }^{18} \mathrm{O}$, the model reaction also reacts well to give the corresponding ${ }^{18} \mathrm{O}$-labelled product $3 \mathbf{3 a a}^{18} \mathrm{O}$ in $84 \%$ yield (Scheme $3 \mathrm{~b}$ ). This outcome confirms that hydroxy oxygen atom in the product should stem from water. 


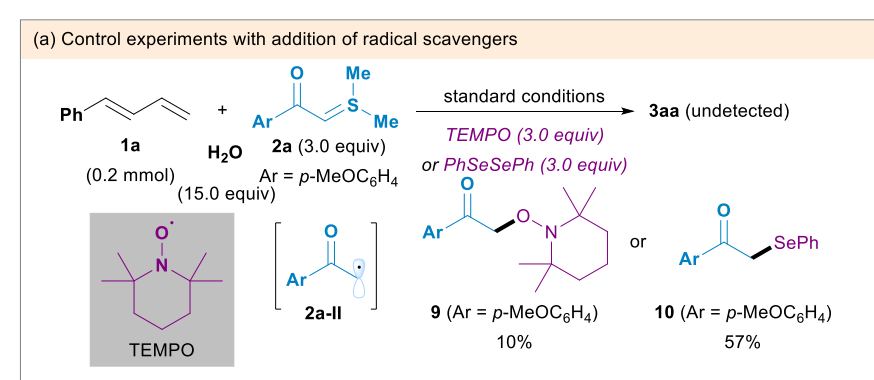

(b) Control experiment with addition of $\mathrm{H}_{2}{ }^{18} \mathrm{O}$
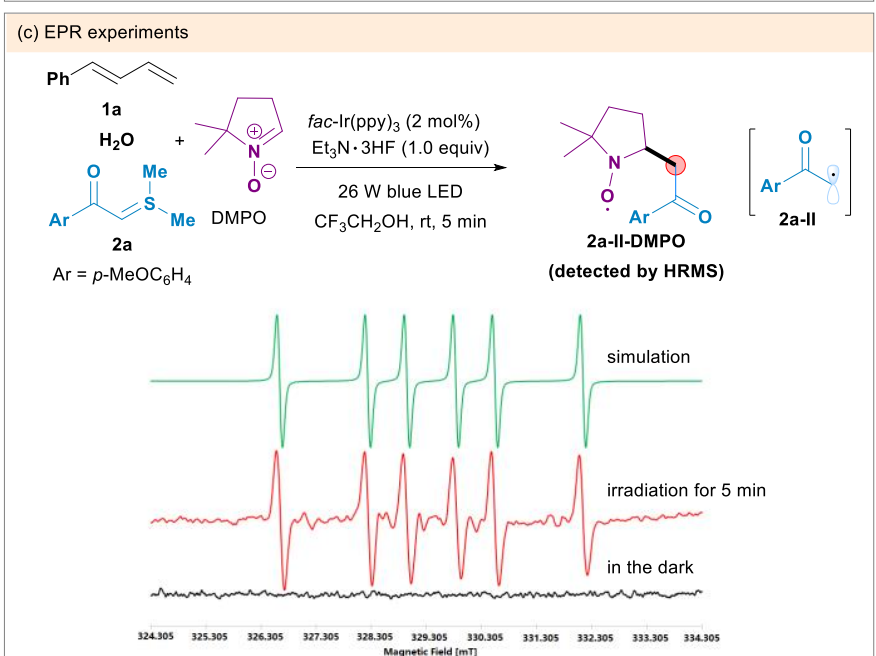

EPR spectra of spin adduct 2a-II-DMPO (X band, $9.8 \mathrm{GHz}, \mathrm{rt}, \mathrm{g}$ value 2.003)

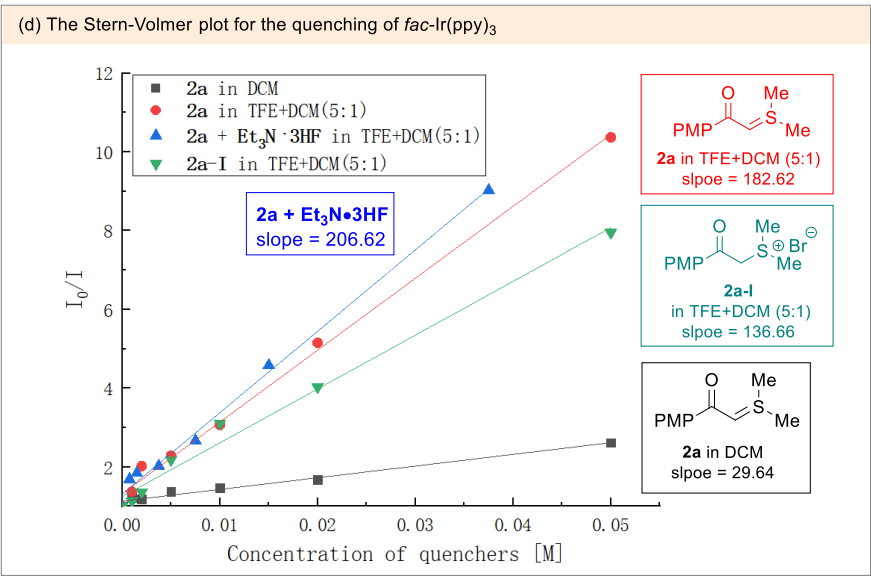

(e) Cyclic voltammogram of sulfur ylide $\mathbf{2 a}$

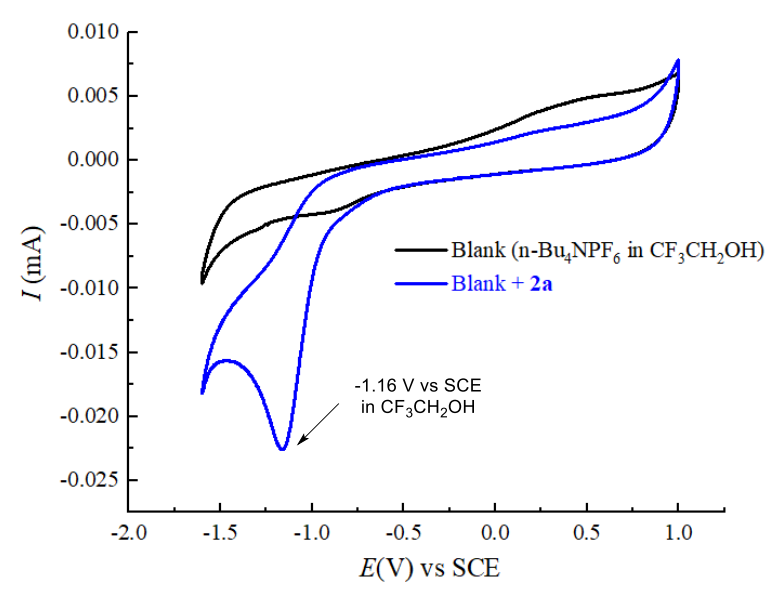

Scheme 3 Mechanistic studies. (a) Radical trapping studies. (b) Control experiment with $\mathrm{H}_{2}{ }^{18} \mathrm{O}$. (c) EPR studies. (d) Stern-Volmer quenching plot of $f a c$-Ir(ppy) ${ }_{3}$ with $\mathbf{2 a}$ (in $\mathrm{CH}_{2} \mathrm{Cl}_{2}$ ), $\mathbf{2 a}$-I (in TFE $/ \mathrm{CH}_{2} \mathrm{Cl}_{2}$ ), $\mathbf{2 a}$ (in TFE/ $\mathrm{CH}_{2} \mathrm{Cl}_{2}$ ), and $\mathbf{2 a} / \mathrm{Et}{ }_{3} \mathrm{~N} \cdot 3 \mathrm{HF}$ (in TFE/CH voltammetry.

Next, we utilized electron paramagnetic resonance (EPR) technique with 5,5-dimethyl-pyrroline $\mathrm{N}$-oxide (DMPO) as a spin trap to investigate radical species possibly engaged in the process. In a mixture of sulfur ylide $2 \mathrm{a}$ and $\mathrm{DMPO}$ in $\mathrm{CF}_{3} \mathrm{CH}_{2} \mathrm{OH}$ under irradiation with blue LED for $5 \mathrm{~min}$, the formation of persistent radical adduct 2a-II-DMPO was confirmed by EPR spectroscopy, a sextet signal with a $g$ value $=2.003, A_{N}=1.597$ $\mathrm{mT}$, and $A_{H}=2.307 \mathrm{mT}$, which was coincident with the carboncentred radical adduct. The simulation EPR spectrum (green trace) was in perfectly agreement with the experimental one (red trace). The adduct 2a-II-DMPO was also confirmed by ESIHRMS spectrometry (Scheme 3c). ${ }^{25}$ Collectively, these outcomes suggest the involvement of $\alpha$-carbonyl carbon radical 2a-II in our reaction.

To further probe the reaction pathway, we then performed the Stern-Volmer luminescence quenching experiments of the photocatalyst $\mathrm{fac}_{-}\left[\mathrm{Ir}(\mathrm{ppy})_{3}\right]$ by gradually increasing the amount of sulfur ylide $\mathbf{2 a}$, its precursor sulfnonium salt $\mathbf{2 a - I}$ and relevant mixture in $\mathrm{CF}_{3} \mathrm{CH}_{2} \mathrm{OH}$ and/or $\mathrm{CH}_{2} \mathrm{Cl}_{2}$ (Scheme $3 \mathrm{~d}$ ). The results reveal that the solutions of sulfur ylide $2 \mathrm{a}$ in the presence or absence of the additive $\mathrm{Et}_{3} \mathrm{~N} \cdot 3 \mathrm{HF}$ in $\mathrm{CF}_{3} \mathrm{CH}_{2} \mathrm{OH} / \mathrm{CH}_{2} \mathrm{Cl}_{2}$ mixture all can quench the excited photocatalyst more efficiently than the sulfonium salt $\mathbf{2 a - 1}$ does, though sulfonium salt $\mathbf{2 a - 1}$ shows somewhat quenching effect. Notably, the combination of $\mathbf{2 a}$ and $\mathrm{Et}_{3} \mathrm{~N} \cdot 3 \mathrm{HF}$ has the strongest quenching effect for photocatalyst. In contrast, sulfur ylide $2 \mathbf{a}$ in $\mathrm{CH}_{2} \mathrm{Cl}_{2}$ shows the weakest quenching effect. To get a deeper insight into the mechanism, we measured reduction potential of the ground states of $2 \mathrm{a}$ to be $-1.16 \mathrm{~V}$ (vs SCE in $\mathrm{CF}_{3} \mathrm{CH}_{2} \mathrm{OH}$ ), ${ }^{25}$ which is inside the redox window of the excited state photocatalyst ${ }^{*}$ fac$\operatorname{Ir}(\mathrm{ppy})_{3}\left(E_{1 / 2} * 111 / \mathrm{IV}=-1.73 \mathrm{~V}\right.$ vs $\left.\mathrm{SCE}\right)$, revealing that our threecomponent reaction may undergo oxidative quenching cycle of 
photocatalyst. ${ }^{27}$ Finally, we determined the quantum yield of the model reaction of $1 \mathbf{a}, \mathbf{2} \mathbf{a}$ and $\mathrm{H}_{2} \mathrm{O}$ to be 0.03 . A value significantly below unit implies that the reaction mainly proceeds through sequential redox events rather than by a radical chain process. ${ }^{25}$

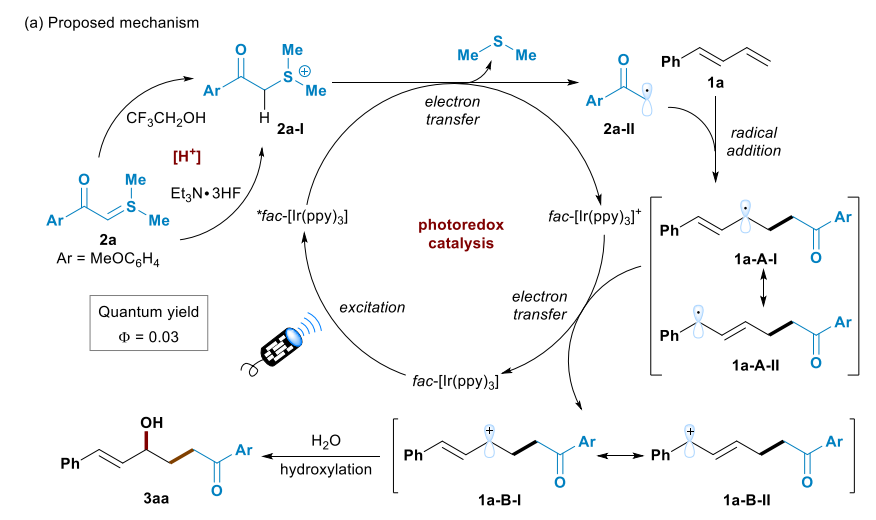

(b) Density functional theory calculations on the reaction profile of carbocation 1a-B
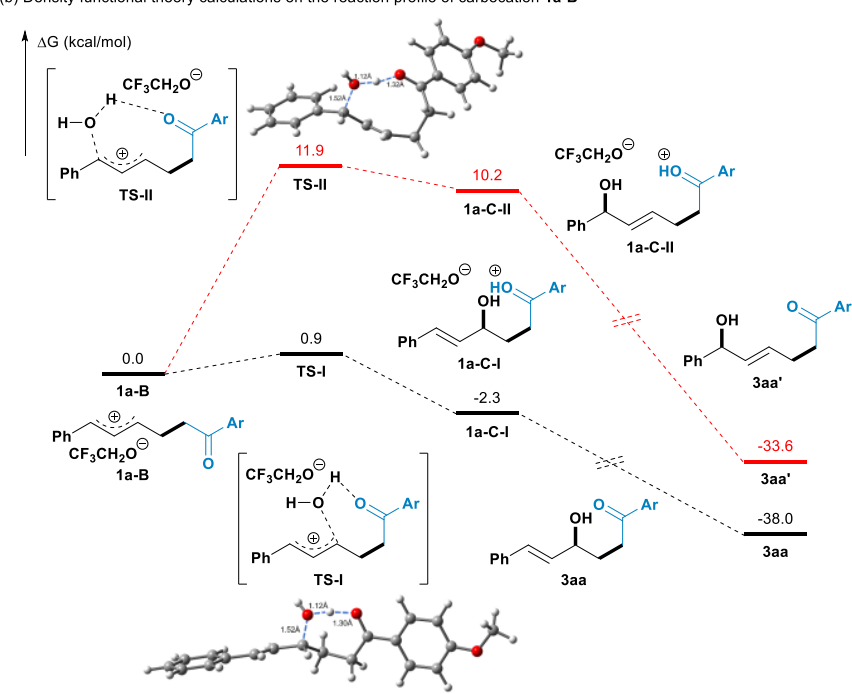

Scheme 4 The proposed mechanism and DFT calculations.

On the basis of these mechanistic studies and literature reports, ${ }^{10-15,} 27$ we then proposed a plausible mechanism with the model reaction of $\mathbf{1 a}, \mathbf{2} \mathbf{a}$ and $\mathrm{H}_{2} \mathrm{O}$ as an example (Scheme $4 a)$. Given the weak basicity of the sulfur ylide $2 a$, it reversibly interacts with $\mathrm{CF}_{3} \mathrm{CH}_{2} \mathrm{OH}$ and/or $\mathrm{Et}_{3} \mathrm{~N} \cdot 3 \mathrm{HF}$ to favour formation of certain amount of the adduct sulfonium salt $2 \mathrm{a}-\mathrm{I},{ }^{28}$ which is susceptible to SET reduction. Then, sulfonium salt 2a-1 undergoes SET reduction by the excited state * $f a c$-[Ir'I(ppy $\left.)_{3}\right]$, also known as an oxidative quenching event, giving the oxidizing sate $f a c-\left[I^{\prime I V}(p p y)_{3}\right]$ and $\alpha$-carbonyl carbon radical $2 a-I I$ with release of dimethyl sulfide. Subsequently, electrophilic 2a-II undergoes intermolecular radical addition across the terminal alkene of 1-phenylbutadiene 1a to furnish new relatively stable carbon radical 1a-A-I or 1a-A-II, which is further oxidized by the oxidizing sate $f a c$ - $\left[\mathrm{r}^{\mathrm{IV}}(\mathrm{ppy})_{3}\right]$ species via another SET process to provide carboncation 1a-B with concurrent regeneration of the ground state photocatalyst $f a c-\left[\mid r^{\prime \prime \prime}(\mathrm{ppy})_{3}\right]$, completing the photoredox catalytic cycle. Finally, an off-photocatalytic cycle nucleophilic attack of $\mathrm{H}_{2} \mathrm{O}$ to the allylic carbocation 1a-B occurs in a highly regioselective manner to afford the corresponding 1,2-hydroxyacylmethylation product 3aa.

To better understand the origin of the regioselectivity involved in the nucleophilic attack of $\mathrm{H}_{2} \mathrm{O}$ to the intermediate carbocation 1a-B, we conducted density functional theory (DFT) calculations on the Gibbs free energy profile of $1 \mathbf{A}-\mathbf{B}$ at the $\omega b 97 x D / 6-311+G^{* *} / / 6-31+G(d)$ level of theory (Scheme $\left.4 b\right) .{ }^{25}$ As allylic carbocation 1a-B-I is in fast equilibrium with benzylic carbocation 1a-B-II, in principle, $\mathrm{H}_{2} \mathrm{O}$ could undergo nucleophilic addition to these two intermediates to form the corresponding 1,2- and 1,4-adducts. Calculations indicated that the attack of $\mathrm{H}_{2} \mathrm{O}$ at the allylic position of 1a-B-I, which goes through $\mathrm{H}$-bondassisted transition state TS-I, generates 1,2-adduct 3aa with a Gibbs free energy barrier of only $0.9 \mathrm{kcal} / \mathrm{mol}$. In contrast, the attack of $\mathrm{H}_{2} \mathrm{O}$ at benzylic position 1a-B-II goes through transition state TS-II and affords 1,4-adduct 3aa' with a Gibbs free energy barrier of $11.9 \mathrm{kcal} / \mathrm{mol}$. The Gibbs free energy gap of TS-I and TS-Il is determined to be $11.0 \mathrm{kcal} / \mathrm{mol}$, which is significantly enough to produce the 1,2-adduct exclusively at room temperature and is in good accordance with the experimental facts. Taken together, sulfur ylides used in the current study not only serve as precursors to $\alpha$-carbonyl carbon radicals, the carbonyl moiety might also act as a $\mathrm{H}$-bond donor to direct the attack of nucleophilic water, thus enabling 1,2difunctionalization as the favoured pathway.

In summary, we have reported a convenient strategy of visible light-driven proton-coupled electron transfer to enable sulfur ylides to decompose into the corresponding $\alpha$-carbonyl carbon radicals. This method allows achievement of a selective 1,2-hydroxyacylmethylation among 1,3-dienes, sulfur ylides and water under photoredox catalysis. This three-component reaction is distinguished by mild conditions, exquisite regioselectivity and broad substrate scope, thus offering a practical complementary method for construction of allylic alcohols. Experimental observations and theoretical calculations shed light on the mechanism and the origin of regioselectivity. The discovered $\mathrm{H}$-bond-activation mode for control of regioselectivity should be of potential use in related synthetic radical chemistry of 1,3-dienes. Work on further expansion of the scope of sulfur ylides and nucleophiles is currently in progress in our laboratory.

\section{Conflicts of interest}

There are no conflicts to declare.

\section{Acknowledgements}

We are grateful to the financial support from the National Natural Science Foundation of China (21971081, 22171099, 21820102003, and 91956201), the Open Research Fund of School of Chemistry and Chemical Engineering, Henan Normal University (2021YB02), and the Program of Introducing Talents of Discipline to Universities of China (111 Program, B17019) for support of this research. 


\section{Notes and references}

1 For selected reviews, see: (a) A.-H. Li, L.-X. Dai and V. K. Aggarwal, Chem. Rev., 1997, 97, 2341-2372; (b) V. K. Aggarwal and C. L. Winn, Acc. Chem. Res., 2004, 37, 611-620; (c) X.-L. Sun and Y. Tang, Acc. Chem. Res., 2008, 41, 937-948; (d) J. Tan, Chin. Sci. Bull., 2018, 63, 3612-3622; (e) D. Kaiser, I. Klose, R. Oost, J. Neuhaus and N. Maulide, Chem. Rev., 2019, 119, 8701-8780; (f) R. Fan, C. Tan, Y. Liu, Y. Wei, X. Zhao, X. Liu, J. Tan and H. Yoshida, Chin. Chem. Lett., 2021, 32, 299-312; $(g)$ C. A. D. Caiuby, L. G. Furniel and A. C. B. Burtoloso, Chem. Sci., 2022, 13, 1192-1209.

2 (a) B. M. Trost, J. Am. Chem. Soc., 1966, 88, 1587-1588; (b) B. M. Trost, J. Am. Chem. Soc., 1967, 89, 138-142; (c) J.-J. Zhang and G. B. Schuster, J. Org. Chem., 1988, 53, 716-719; (d) S. A. Stoffregen, M. Heying and W. S. Jenks, J. Am. Chem. Soc., 2007, 129, 15746-15747; (e) A. J. Mortimer, A. E. Aliev, D. A. Tocher and M. J. Porter, Org. Lett., 2008, 10, 5477-5480.

3 (a) B. F. Yates, W. J. Bouma and L. Radom, J. Am. Chem. Soc., 1984, 106, 5805-5808; (b) B. F. Yates, W. J. Bouma and L. Radom, J. Am. Chem. Soc., 1987, 109, 2250-2263.

4 J.-J. Zhang and G. B. Schuster, J. Am. Chem. Soc., 1989, 111, 7149-7155.

5 (a) M. M. D. Pramanik, F. Yuan, D.-M. Yan, W.-J. Xiao and J.-R. Chen, Org. Lett., 2020, 22, 2639-2644. (b) F. Yuan, D.-M. Yan, P.-P. Gao, D.-Q. Shi, W.-J. Xiao and J.-R. Chen, ChemCatChem, 2021, 13, 543-547; (c) P.-P. Gao, D.-M. Yan, M.-H. Bi, M. Jiang, W.-J. Xiao and J.-R. Chen, Chem. Eur. J., 2021, 27, 14195-14201.

6 For selected reviews, see: (a) J. P. Goddard, C. Ollivier and L. Fensterbank, Acc. Chem. Res., 2016, 49, 1924-1936; (b) J. M. Smith, J. A. Dixon, J. N. deGruyter and P. S. Baran, J. Med. Chem., 2019, 62, 2256-2264; (c) S. P. Pitre, N. A. Weires and L. E. Overman, J. Am. Chem. Soc., 2019, 141, 2800-2813; (d) S. Crespi and M. Fagnoni, Chem. Rev., 2020, 120, 9790-9833; (e) (f) P. Gao, Y.-J. Niu, F. Yang, L.-N. Guo and X.-H. Duan, Chem. Commun., 2022, 58, 730-746; $(g)$ V. Corce, C. Ollivier and L. Fensterbank, Chem. Soc. Rev., 2022, 10.1039/d1cs01084k; $(h)$ D. M. Kitcatt, S. Nicolle and A. L. Lee, Chem. Soc. Rev., 2022, $10.1039 / \mathrm{d} 1 \mathrm{cs} 01168 \mathrm{e}$.

7 For selected reviews, see: (a) C. K. Prier, D. A. Rankic and D. W. MacMillan, Chem. Rev., 2013, 113, 5322-5363; (b) D. Ravelli, M. Fagnoni and A. Albini, Chem. Soc. Rev., 2013, 42, 97-113; (c) D. M. Schultz and T. P. Yoon, Science, 2014, 343, 985-994; (d) P. Wang, Q. Zhao, W. Xiao and J. Chen, Green Synth. Catal., 2020, 1, 42-51; (e) Y. Sumida and H. Ohmiya, Chem. Soc. Rev., 2021, 50, 6320-6332; (f) B. Lu, W.-J. Xiao and J.-R. Chen, Molecules, 2022, 27, 517; (g) F.-D. Lu, J. Chen, X. Jiang, J.-R. Chen, L.-Q. Lu and W.-J. Xiao, Chem. Soc. Rev., 2021, 50, 12808-12827.

8 For selected reviews, see: ( $a$ ) L. Fensterbank, J. P. Goddard, M. Malacria and C. Ollivier, Chimia, 2012, 66, 425-432; (b) Y. Wang, Y. Li and X. Jiang, Chem. Asian J., 2018, 13, 2208-2242 (c) C. B. Kelly and R. Padilla-Salinas, Chem. Sci., 2020, 11, 10047-10060; (d) J. Gao, J. Feng and D. Du, Chem. Asian. J., 2020, 15, 3637-3659; (e) A. Peter, G. J. P. Perry and D. J. Procter, Adv. Synth. Catal., 2020, 362, 2135-2142.

9 For early pioneering reports, see: $(a)$ T. Laird and H. Williams, J. Chem. Soc. D, 1969, 561-562; (b) J. W. Knapczyk and W. E. McEwen, J. Org. Chem., 1970, 35, 2539-2543; (c) J. L. Dektar and N. P. Hacker, J. Am. Chem. Soc., 1990, 112, 6004-6015; (d) F. D. Saeva, D. T. Breslin and H. R. Luss, J. Am. Chem. Soc., 1991, 113, 5333-5337.

10 (a) F. Berger, M. B. Plutschack, J. Riegger, W. Yu, S. Speicher, M. Ho, N. Frank and T. Ritter, Nature, 2019, 567, 223-228; (b) F. Ye, F. Berger, H. Jia, J. Ford, A. Wortman, J. Borgel, C. Genicot and T. Ritter, Angew. Chem. Int. Ed., 2019, 58, 1461514619.
11 (a) Y. L. Zhang, L. Yang, J. Wu, C. Zhu and P. Wang, Org. Lett., 2020, 22, 7768-7772; (b) J. Wu, Z. Wang, X.-Y. Chen, Y. Wu, D. Wang, Q. Peng and P. Wang, Sci. China Chem., 2020, 63, 336340.

12 M. H. Aukland, M. Šiaučiulis, A. West, G. J. P. Perry and D. J. Procter, Nat. Catal., 2020, 3, 163-169.

13 (a) C. Chen, M. Wang, H. Lu, B. Zhao and Z. Shi, Angew. Chem. Int. Ed., 2021, 60, 21756-21760; (b) C. Chen, Z. J. Wang, H. Lu, Y. Zhao and Z. Shi, Nat. Commun., 2021, 12, 4526.

14 X. Li, C. Golz and M. Alcarazo, Angew. Chem. Int. Ed., 2021, 60, 6943-6948.

15 (a) X. Zhu, M. Jiang, X. Li, E. Zhu, Q. Deng, X. Song, J. Lv and D. Yang, Org. Chem. Front., 2022, 9, 347-355; (b) X. Li, M. Jiang, X. Zhu, X. Song, Q. Deng, J. Lv and D. Yang, Org. Chem. Front., 2022, 9, 386-393.

16 (a) X.-Y. Yu, Q.-Q. Zhao, J. Chen, W.-J. Xiao and J.-R. Chen, Acc. Chem. Res., 2020, 53, 1066-1083; (b) P.-Z. Wang, Y. Gao, J. Chen, X.-D. Huan, W.-J. Xiao and J.-R. Chen, Nat. Commun., 2021, 12, 1815; (c) H. Qian, J. Chen, B. Zhang, Y. Cheng, W.-J. Xiao and J.-R. Chen, Org. Lett., 2021, 23, 6987-6992; (d) L.-P. Tan, D. Liang, Y. Cheng, W.-J. Xiao and J.-R. Chen, Org. Chem. Front., 2021, 8, 5052-5057.

17 (a) D. R. Weinberg, C. J. Gagliardi, J. F. Hull, C. F. Murphy, C. A. Kent, B. C. Westlake, A. Paul, D. H. Ess, D. G. McCafferty and T. J. Meyer, Chem. Rev., 2012, 112, 4016-4093; (b) R. Knowles and H. Yayla, Synlett, 2014, 25, 2819-2826; (c) L. Q. Nguyen and R. R. Knowles, ACS Catal., 2016, 6, 2894-2903; (d) N. Hoffmann, Eur. J. Org. Chem., 2017, 1982-1992; (e) Z. Zhou, X. Kong and T. Liu, Chin. J. Org. Chem., 2021, 41, 3844-3879.

18 S. H. Mashraqui and R. M. Kellogg, Tetrahedron Lett., 1985, 26 1453-1456.

19 (a) T. M. Monos, G. Magallanes, L. J. Sebren and C. R. J. Stephenson, J. Photochem. Photobiol., A, 2016, 328, 240-248; (b) X.-H. Ouyang, R.-J. Song and J.-H. Li, Chem. Asian J., 2018, 13, 2316-2332.

20 For selected examples, see: (a) D. A. Nicewicz and D. W. C. MacMillan, Science, 2008, 322, 77-80; (b) Y. Su, L. Zhang and N. Jiao, Org. Lett., 2011, 13, 2168-2171; (c) H. Huo, X. Shen, C. Wang, L. Zhang, P. Röse, L.-A. Chen, K. Harms, M. Marsch, G. Hilt and E. Meggers, Nature, 2014, 515, 100-103; (d) Y.-B. Zhu, L. Zhang and S.-Z. Luo, J. Am. Chem. Soc., 2014, 136, 1464214645; (e) W. Chen, Z. Liu, J. Tian, J. Li, J. Ma, X. Cheng and G. Li, J. Am. Chem. Soc., 2016, 138, 12312-12315; $(f)$ J. Cheng, X. Deng, G. Wang, Y. Li, X. Cheng and G. Li, Org. Lett., 2016, 18, 4538-4541; $(g)$ N. Esumi, K. Suzuki, Y. Nishimoto and M. Yasuda, Org. Lett., 2016, 18, 5704-5707; $(h)$ D. Zheng and A. Studer, Angew. Chem. Int. Ed., 2019, 58, 15803-15807; (i) S. Das, T. Mandal and S. De Sarkar, Adv. Synth. Catal., 2022, 364, 755-765; (j) H. Liang, D.-S. Ji, G.-Q. Xu, Y.-C. Luo, H. Zheng and P.-F. Xu, Chem. Sci., 2022, 13, 1088-1094.

21 (a) E. D. Nacsa and D. W. C. MacMillan, J. Am. Chem. Soc., 2018 140, 3322-3330; (b) E. D. Nacsa and D. W. C. MacMillan, J. Am. Chem. Soc., 2018, 140, 3322-3330; (c) E. Speckmeier, P. J. W. Fuchs and K. Zeitler, Chem. Sci., 2018, 9, 7096-7103.

22 For a recent review, see: (a) P.-Z. Wang, W.-J. Xiao and J.-R. Chen, Chin. J. Catal., 2022, 43, 548-557; for selected examples, see: $(b)$ K. P. Shing Cheung, D. Kurandina, T. Yata and V. Gevorgyan, J. Am. Chem. Soc., 2020, 142, 9932-9937; (c) H.-M. Huang, P. Bellotti, P. M. Pfluger, J. L. Schwarz, B. Heidrich and F. Glorius, J. Am. Chem. Soc., 2020, 142, 10173-10183; (d) P. Bellotti, M. Koy, C. Gutheil, S. Heuvel and F. Glorius, Chem. Sci. 2021, 12, 1810-1817; (e) F. Li, S. Lin, Y. Chen, C. Shi, H. Yan, C. $\mathrm{Li}, \mathrm{C}$. Wu, L. Lin, C. Duan and L. Shi, Angew. Chem. Int. Ed., 2021, 60, 1561-1566; (f) W. Guo, Q. Wang and J. Zhu, Angew. Chem. Int. Ed., 2021, 60, 4085-4089; (g) K. P. Shing Cheung, D. Kurandina, T. Yata and V. Gevorgyan, J. Am. Chem. Soc., 2020, 142, 9932-9937; (h) F.-D. Lu, L.-Q. Lu, G.-F. He, J.-C. Bai and W.-J. Xiao, J. Am. Chem. Soc., 2021, 143, 4168-4173; (i) Z.-L. 
Liu, Z.-P. Ye, Y.-X. Chen, Y. Zheng, Z.-Z. Xie, J.-P. Guan, J.-A. Xiao, K. Chen, H.-Y. Xiang and H. Yang, Org. Lett., 2022, 24, 924-928; (k) J. Zheng, N. Tang, H. Xie and B. Breit, Angew. Chem. Int. Ed., 2022, 61, 10.1002/anie.202200105.

23 (a) J. Chen, Y.-J. Liang, P.-Z. Wang, G.-Q. Li, B. Zhang, H. Qian, X.-D. Huan, W. Guan, W.-J. Xiao and J.-R. Chen, J. Am. Chem. Soc., 2021, 143, 13382-13392; (b) P.-Z. Wang, X. Wu, Y. Cheng, M. Jiang, W.-J. Xiao and J.-R. Chen, Angew. Chem. Int. Ed., 2021, 60, 22956-22962; (c) H. Zhou and X.-Y. Liu, Chin. J. Org. Chem., 2021, 41, 4510-4511.

24 (a) H.-M. Huang, P. Bellotti and F. Glorius, Chem. Soc. Rev. 2020, 49, 6186-6197; (b) P. Hünemörder and E. Mejía, Catal. Sci. Technol., 2020, 10, 6754-6768; (c) M.-M. Zhang, Y.-N. Wang, L.-Q. Lu and W.-J. Xiao, Trends Chem., 2020, 2, 764-775; (d) H. Yue, C. Zhu, L. Huang, A. Dewanji and M. Rueping, Chem. Commun., 2021, 58, 171-184.

25 Please see the $\mathrm{ESI}, \uparrow$ for more details.

26 (a) L. Yang, W.-W. Ji, E. Lin, J.-L. Li, W.-X. Fan, Q. Li and H. Wang, Org. Lett., 2018, 20, 1924-1927; (b) Y.-F. Yang, J.-H. Lin and J.C. Xiao, Org. Lett., 2021, 23, 9277-9282; (c) R. A. Fernandes, A. J. Gangani and A. Panja, Org. Lett., 2021, 23, 6227-6231.

27 (a) S. Otsuka, K. Nogi, T. Rovis and H. Yorimitsu, Chem. Asian. J., 2019, 14, 532-536; (b) L. Flamigni, A. Barbieri, C. Sabatini, B. Ventura and F. Barigelletti, Top. Curr. Chem., 2007, 281, 143203.

28 (a) W. Guo, M. Wang, Z. Han, H. Huang and J. Sun, Chem. Sci., 2021, 12, 11191-11196; (b) A. J. Boyington, M. Y. Riu and N. T. Jui, J. Am. Chem. Soc., 2017, 139, 6582-6585; (c) S.-Y. Guo, F. Yang, T.-T. Song, Y.-Q. Guan, X.-T. Min, D.-W. Ji, Y.-C. Hu and Q.-A. Chen, Nat. Commun., 2021, 12, 6538. 